\title{
PALEOCLIMATE DATA CONSTRAINTS ON CLIMATE SENSITIVITY: THE PALEOCALIBRATION METHOD*
}

\author{
CURT COVEY \\ Global Climate Research Division, Mail Code L-264, Lawrence Livermore National Laboratory, \\ Livermore, CA 94551, U.S.A. \\ LISA CIRBUS SLOAN \\ Institute of Marine Sciences, University of California, Santa Cruz, CA 95064, U.S.A. \\ and \\ MARTIN I. HOFFERT \\ Department of Earth Systems Science, New York University, New York, NY 10003, U.S.A.
}

\begin{abstract}
The relationship between paleoclimates and the future climate, while not as simple as implied in the 'paleoanalog' studies of Budyko and others, nevertheless provides sufficient constraints to broadly confirm the climate sensitivity range of theoretical models and perhaps eventually narrow the model-derived uncertainties. We use a new technique called 'paleocalibration' to calculate the ratio of temperature response to forcing on a global mean scale for three key intervals of Earth history. By examining surface conditions reconstructed from geologic data for the Last Glacial Maximum, the middle Cretaceous and the early Eocene, we can estimate the equilibrium climate sensitivity to radiative forcing changes for different extreme climates. We find that the ratios for these three periods, within error bounds, all lie in the range obtained from general circulation models: $2-5 \mathrm{~K}$ global warming for doubled atmospheric carbon dioxide. Paleocalibration thus provides a data-based confirmation of theoretically calculated climate sensitivity. However, when compared with paleodata on regional scales, the models show less agreeement with data. For example, our GCM simulation of the early Eocene fails to obtain the temperature contrasts between the Equator and the Poles (and between land and ocean areas) indicated by the data, even though it agrees with the temperature data in the global average. Similar results have been reported by others for the Cretaceous and for the Last Glacial Maximum.
\end{abstract}

\section{Introduction}

Climate sensitivity can be defined as the eventual (or equilibrium) change in global mean surface temperature in response to a prescribed change in global mean radiative forcing. A conventional measure of climate sensitivity is the global warming $\Delta T_{2 \times}$ expected from doubling atmospheric $\mathrm{CO}_{2}$. Although this definition excludes time-dependent effects and regional details, it serves as a first approximation for approaching the issue of future global change. General circulation models of climate obtain $\Delta T_{2 \times}$ in the approximate range $2-5 \mathrm{~K}$. Over the last two decades, no GCM with reasonable input assumptions has obtained a sensitivity much outside the $2-5 \mathrm{~K}$ range. At the same time it has proved all too easy, by varying a model's assumptions within the bounds of plausibility, to move its sensitivity from one extreme end of the range to the other (e.g., Mitchell et al., 1989).

* The U.S. Government right to retain a non-exclusive royalty-free license in and to any copyright is acknowledged. 
As an alternative to model-based predictions, Kellogg (1977) and Budyko and Izrael (1987) offered a 'paleoanalog' approach based on direct analogy with past warm periods. This method involves modeling the detailed time- and spacedependent details of future climate by analogy with past climatic changes. The problem with this method, however, is that Twenty-First Century global warming would probably involve unprecedented rates of climatic change for which there are no satisfactory geologic analogs (Crowley, 1990). A less ambitious but more justifiable approach - 'paleocalibration' - originated with Lorius et al. (1990). These authors used geologic data from the Last Glacial Maximum (LGM, 20 thousand years ago) to infer $\Delta T_{2 \times}$ without attempting to forecast the time-evolving behavior or regional details of the future climate. We extended the paleocalibration approach to the warm mid-Cretaceous era of 100 million years ago (Hoffert and Covey, 1992). In this paper we compare our paleocalibration results with more recent results of others, we discuss a fundamental criticism of the technique (Lindzen, 1993), and we introduce a new paleocalibration data point, representing the early Eocene (55 million years ago).

Examination of paleoclimates with GCMs, the same models that predict future global warming, has been pursued for well over a decade (e.g., Hecht, 1985; Crowley and North, 1991). Although the paleocalibration technique is independent of GCMs, it leads naturally to questions of model fidelity in simulating paleoclimates. We conclude this paper with the results of new GCM simulations of the Eocene that address this point.

\section{Method}

In principle the paleocalibration technique is straightforward. For a given time interval, one obtains both the difference from present-day globally averaged surface temperature $(\Delta T)$ and the difference from the present-day globally averaged radiative forcing $(\Delta Q) . \Delta T$ is obtained from whatever geologic proxies are available. $\Delta Q$ is derived by calculating or estimating the total effect of the heat trapped by greenhouse gases and the changes in absorption of solar radiation due to changes in solar luminosity, surface albedo and atmospheric aerosol content. The next and final step is simply to define the ratio $\Delta T / \Delta Q$ as the climate sensitivity, which is the global temperature response to the radiative forcing.

As an example, Hansen et al. (1993) estimated that for the Last Glacial Maximum, $\Delta T$ was $-5 \mathrm{~K}$ and $\Delta Q$ was $-7 \mathrm{~W} \mathrm{~m}^{-2}$. Most of $\Delta Q$ arises from continental ice sheets and atmospheric aerosols reflecting more solar energy back to space (ice core samples from the LGM clearly show that the atmosphere then contained much more dust than at present, though the exact amount it contained is controversial). A secondary term is the decreased trapping of infrared radiation due to smaller atmospheric amounts of $\mathrm{CO}_{2}$ and $\mathrm{CH}_{4}$. The $\Delta T / \Delta Q$ ratio is $\left.0.7 \mathrm{~K}_{(\mathrm{W} \mathrm{m}}^{-2}\right)^{-1}$. This quantity can be converted to a value for comparison with global warming 
estimates by noting that a doubling of atmospheric $\mathrm{CO}_{2}$ traps about $4 \mathrm{~W} \mathrm{~m}^{-2}$ of infrared radiation. Then, using the values from Hansen $e t$ al., the expected global warming due to doubled $\mathrm{CO}_{2}$ would be $(0.7) \times 4=3 \mathrm{~K}$, in the middle of the range of GCM estimates.

There are important limitations to the paleocalibration technique. First, the climate sensitivity as defined above says nothing about how long the system would take to respond to a given forcing. In the case of future global warming, the heat capacity of the oceans would introduce a lag time, which predictions of future climate would need to account for by means other than paleocalibration. Note, however, that the primary factor determining the lag time is the equilibrium sensitivity value itself (Hansen et al., 1985; Wigley and Schlesinger, 1985). A second limitation of paleocalibration is that it determines only the globally averaged temperature response, not the pattern of regional response (nor the responses of other climatically important quantities like precipitation). As we discuss below, GCMs generally fail to simulate the observed difference in temperature response between Equator and Poles or between land and sea. Thus reliable forecasts of future regional climates are not yet obtainable from either paleocalibration or theoretical climate models.

A further subtlety comes in the definition of $\Delta Q .4 \mathrm{~W} \mathrm{~m}^{-2}$, for example, is the infrared trapping caused by doubled $\mathrm{CO}_{2}$ in the absence of other effects or feedbacks such as changes in temperature, cloudiness or atmospheric water vapor content. $\Delta Q$ is defined as the total change in radiative flux at the top of the troposphere due only to changes in greenhouse gases, surface albedo, atmospheric aerosol content and solar luminosity. It may be thought of as the result of hypothetical, instantaneous changes in the above-mentioned factors, before temperature, clouds or water vapor have a chance to respond. Note also that by defining $\Delta Q$ as the instantaneous change in flux at the top of the troposphere ( $\sim 10 \mathrm{~km}$ altitude), rather than at the top of the atmosphere, we exclude the stratospheric cooling effect of enhanced greenhouse gases. Instantaneous doubling of $\mathrm{CO}_{2}$, for example, reduces outgoing infrared flux by about $4 \mathrm{~W} \mathrm{~m}^{-2}$ at the top of the troposphere but by only about $2 \mathrm{~W}$ $\mathrm{m}^{-2}$ at the top of the atmosphere (e.g., Lindzen, 1995; Hansen et al., 1995). This difference in flux reduction is due to enhanced infrared emission to space by the stratosphere, caused by the increased concentration of IR-emitting $\mathrm{CO}_{2}$ molecules there. The flux divergence in the stratosphere leads to cooling of that region. Within a few months of instantaneous $\mathrm{CO}_{2}$ doubling, the stratosphere would thus adjust its temperature so that the flux change would be about $4 \mathrm{~W} \mathrm{~m}^{-2}$ at both the top of the atmosphere and the top of the troposphere (Hansen et al., 1981). For this reason the definition of $\Delta Q$ as flux change at the top of the troposphere provides an appropriate measure of climate forcing. Another way to put the argument is that the entire troposphere is convectively coupled to the surface, while stratospheric temperature changes are decoupled from tropospheric temperature changes (Cess and Potter, 1988; Shine et al., 1990). 
The actual climate would of course change continuously with changing radiative forcing, so $\Delta Q$ cannot be measured directly. For example, one cannot expect satellite observations to record a decrease of several $\mathrm{W} \mathrm{m}^{-2}$ in the infrared flux of Earth to space as greenhouse gases increase. Instead one would expect atmospheric temperature to increase to restore an approximate balance of absorbed solar energy and emitted infrared (i.e., global warming due to an enhanced greenhouse effect). $\Delta Q$ is well defined, however, despite its hypothetical nature. Given a specified set of changes in greenhouse gases, aerosols and surface albedo, $\Delta Q$ can be found as a straightforward exercise in radiative transfer.

In short, paleocalibration defines the climatic feedbacks involved in cloud and water vapor changes to be part of the response $\Delta T$ rather than part of the forcing $\Delta Q$. The technique in effect measures the sum of cloud and water vapor feedbacks by observing $\Delta T$. On the other hand, much slower processes like changes in atmospheric $\mathrm{CO}_{2}$ and the growth and decay of continental ice sheets are included in $\Delta Q$, the forcing. Distinguishing the fast feedbacks contained in $\Delta T$ from the forcing factors in $\Delta Q$ is thus a matter of time-scale separation. Paleocalibration does not aim to identify the root causes of past climatic changes, such as the causes of ice sheet growth and decay or of glacial-to-interglacial greenhouse gas variations. Instead the technique aims to measure the feedbacks that translate such root causes into temperature change. Feedbacks due to clouds and water vapor account for most of the uncertainty in the model estimates of future global warming.

\section{Review of Results and a Fundamental Criticism}

Table I compares our previous results (Hoffert and Covey, 1992) with subsequent estimates of Barron (1993) and Hansen et al. (1993). Note that we estimated $\Delta T / \Delta Q$ for both the Cretaceous and the LGM, whereas Barron dealt with the Cretaceous only, and Hansen et al. dealt with the LGM only. Both our Cretaceous and LGM estimates gave $\Delta T_{2 \times} \sim 2 \mathrm{~K}$, at the low end of the GCM prediction range. On the other hand, the LGM estimate of Hansen et al. gave $\Delta T_{2 \times} \sim 3 \mathrm{~K}$, near the center of the GCM range, and the Cretaceous estimate of Barron gave $\Delta T_{2 \times} \sim 4 \mathrm{~K}$, in the upper half of the range.

The difference between our estimate and that of Hansen et al. arises from differing values of $\Delta T$ we used for the LGM. We used $\Delta T \approx-3 \mathrm{~K}$, obtained by taking a global average of the sea surface temperatures compiled by the CLIMAP analysis of LGM data. For land areas we simply assumed that the LGM cooling was identical to that of ocean areas in the same latitude zones. This assumption was based on the general principle that the atmosphere efficiently smoothes out temperature contrasts between land and sea within each latitude zone. It ignores residual land-sea temperature differences in climatic equilibrium, which, according to GCM simulations, would increase the global mean Ice Age cooling by an additional 0.5-1 K (Crowley and North, 1991, p. 79). Furthermore, some terrestrial 
TABLE I

Intercomparison of paleocalibration estimates

\begin{tabular}{llll}
\hline & $\Delta T[\mathrm{~K}]$ & $\Delta Q\left[\mathrm{~W} \mathrm{~m}{ }^{-2}\right]$ & $\Delta T_{2 \times \mathrm{CO}_{2}[\mathrm{~K}]}$ \\
\hline $\begin{array}{l}\text { Hoffert and Covey (1992) } \\
\quad \text { LGM }\end{array}$ & $-3 \pm 0.6$ & $-6.7 \pm 0.9$ & $2 \pm 0.5$ \\
$\begin{array}{l}\text { Hansen } \text { et al. (1993) } \\
\quad \text { LGM }\end{array}$ & $-5 \pm 1$ & $-7.1 \pm 1.5$ & $3 \pm 1$ \\
$\begin{array}{l}\text { Hoffert and Covey (1992) } \\
\quad \text { Cretaceous }\end{array}$ & $9 \pm 2$ & $15.7 \pm 6.8$ & $2.5 \pm 1.2$ \\
$\begin{array}{l}\text { Barron (1993) } \\
\quad \text { Cretaceous }\end{array}$ & $7 \pm 2$ & $8 \pm 3.5$ & $3.8 \pm 2.0$ \\
\hline
\end{tabular}

geologic data suggest that the actual Ice Age cooling over land was substantially larger than that over ocean (Rind and Peteet, 1985). Based on this consideration, Hansen $e t$ al. chose $\Delta T \approx-5 \mathrm{~K}$ for the LGM and obtained a correspondingly higher estimate of $\Delta T_{2 \times}$ than ours. It has also been suggested that the tropical ocean $\Delta T$ values obtained by CLIMAP are too small in magnitude (Guilderson et al., 1994). If this additional consideration is taken into account, the magnitude of Ice Age $\Delta T$ - and the inferred climate sensitivity - could exceed Hansen's estimate.

Barron's discussion of $\Delta T_{2 \times}$ provides a further gauge of uncertainty in paleocalibration, although it was not presented as such. (See also Barron et al., 1995, which reaches similar conclusions from a somewhat different point of view.) He estimated Cretaceous $\Delta T \sim 7 \mathrm{~K}$ (an update of his earlier work, which had previously given a best guess of $9 \mathrm{~K}$ ). He then considered possible combinations of $\Delta T_{2 \times}$ and $\mathrm{CO}_{2}$ amounts that could achieve the Cretaceous warming. For example, $7 \mathrm{~K}$ warming could result either from $\Delta T_{2 \times}=5 \mathrm{~K}$ and 2.6 times present-day $\mathrm{CO}_{2}$, or from $\Delta T_{2 \times}=2 \mathrm{~K}$ and 11 times present-day $\mathrm{CO}_{2}$ (assuming logarithmic scaling of $\mathrm{CO}_{2}$ radiative forcing with $\mathrm{CO}_{2}$ amount). Thus a $2-5 \mathrm{~K}$ range of $\mathrm{GCM}$ sensitivity to $\mathrm{CO}_{2}$ doubling, together with the observation that $\Delta T \sim 7 \mathrm{~K}$, implies Cretaceous $\mathrm{CO}_{2}$ amounts ranging from 3 to 11 times present. Considering 2-6 times present atmospheric $\mathrm{CO}_{2}$ as the likely range of actual Cretaceous $\mathrm{CO}_{2}$ amounts, Barron inferred that the climate's true $\Delta T_{2 \times}$ must be significantly greater than $2 \mathrm{~K}$ in order to bring the implied Cretaceous $\mathrm{CO}_{2}$ amounts within reasonable bounds. In the table we have put Barron's numbers into the paleocalibration format, using $\Delta T \approx 7 \mathrm{~K}$ and calculating $\Delta Q$ from a 2-6 fold increase in $\mathrm{CO}_{2}$. Application of the formal error analysis that we used for our own estimates (Hoffert and Covey, 1992, Eqn. 4) results in $\Delta T_{2 \times}$ spanning a broad range, as shown in the table. The center of the estimate, however, is noticeably larger than the climate sensitivity that we inferred from the Cretaceous. The table shows the reason for the difference: our 
$\Delta Q$ was twice as large as that resulting from only a 2-6 fold increase in $\mathrm{CO}_{2}$. The main reason for this discrepancy is that we considered changes in surface albedo as well as greenhouse gases when we estimated $\Delta Q$. Cretaceous surface albedo that was lower than present makes a contribution to $\Delta Q$ of nearly $6 \mathrm{~W} \mathrm{~m}^{-2}$ in the Hoffert-Covey estimate. Our larger $\Delta Q$, together with approximately the same $\Delta T$, implies a smaller climate sensitivity $\Delta T / \Delta Q$.

It should be noted in passing that a recent revision of Cretaceous temperatures by Sellwood et al. (1994) obtained 'minimum estimates' somewhat cooler than the Barron's lower limits. Sellwood et al., however, failed to consider the substantial Equator-to-Pole gradient in the background sea water value of oxygen isotope ratio (their proxy for temperature). Taking this gradient into account substantially increases the tropical temperatures inferred from oxygen isotopes (Zachos et al., 1994; Crowley and Kim, 1995).

The most important conclusion from Table $I$ is that paleocalibration gives roughly the same range of possible values for $\Delta T_{2 \times}$ as GCMs do. Although it does not change the conventional wisdom about the magnitude of potential human-induced climatic changes, paleocalibration strengthens the GCM-based theory by providing independent confirmation. Of course it would be useful if paleodata could be used to narrow the range of uncertainty in $\Delta T_{2 \times}$. Our own previous results (Hoffert and Covey, 1992) and the preliminary Eocene analysis given in the following section imply that $\Delta T_{2 \times}$ lies at the low end of GCM predictions. As discussed above, however, alternate interpretations of the paleodata can push $\Delta T_{2 \times}$ upward. We must admit that our estimate of $3 \mathrm{~K}$ for Ice Age cooling is smaller than the consensus value among paleoclimatologists. Further, our $\pm 0.6 \mathrm{~K}$ LGM error limits accounted only for the scatter of CLIMAP longitude-averaged sea surface temperatures relative to a smooth curve, not the range of different interpretations of the paleodata.

In addition to controversy over the most appropriate input values for the paleocalibration technique, there are fundamental objections to the technique itself. Paleocalibration makes the basic assumption that globally averaged temperature response depends on the globally averaged forcing, i.e., that $\Delta T$ is a unique function of $\Delta Q$. Lindzen (1993) has asserted to the contrary that under "an altered distribution of heating ... major changes in global climate may occur, even if the sensitivity to changing $\mathrm{CO}_{2}$ is extremely small [emphasis added]." Although Lindzen did not give the details of his argument, it is evidently based on observations that: (1) tropical temperatures have shown very little increase during warm periods in Earth history; and (2) poleward fluxes of heat outside the tropics are dominated by baroclinic eddy transports (at least in the present-day atmosphere). If the threshold for baroclinic instability depends on meridional temperature gradient, then that gradient may remain largely fixed. Thus, if tropical temperatures do not respond much to increased $\mathrm{CO}_{2}$, middle and high latitude temperatures also may not. 
The paleoclimatic record, however, poses serious problems for dynamical theories in which extratropical heat fluxes are always dominated by baroclinic eddies. Relatively small tropical warmings have been accompanied on many occasions by substantial warmings at higher latitudes. This observation directly contradicts the theoretical prediction that meridional temperature gradient is largely fixed outside the tropics. For example, examination of the data summarized by Hoffert and Covey (1992) demonstrates that during the Cretaceous, the Equator-Pole temperature contrast was about one-half its present value. Increased poleward heat flows are required to explain the warmer high-latitude regions, despite the strong positive dependence of baroclinic heat flux on meridional temperature gradient. The apparent increase in heat flow despite a reduction in temperature gradient (presumably accomplished by processes other than baroclinic eddies) implies that energy fluxes in temperature latitudes can be substantially independent of the temperature structure there.

Related questions about paleocalibration come to mind from the geologic record. The coming and going of Ice Ages are clearly associated with Milankovitch forcing: small changes in the distribution of insolation, caused in turn by small variations in Earth's orbit about the Sun (Imbrie and Imbrie, 1979). Also, the glacial-interglacial $\mathrm{CO}_{2}$ variations that comprise the main part of Ice Age $\Delta Q$ may themselves be caused by glacial-interglacial climate changes. So how can one infer climate sensitivity from them?

The answer to these questions is that paleocalibration does not attempt to identify root causes of climatic change, only to measure the feedbacks that determine the level of response to those root causes and result in the observed paleotemperatures. Thus, Milankovitch forcing may well trigger the growth of continental ice sheets, but it is difficult to explain 3-5 K global cooling during Ice Ages without invoking positive feedbacks that amplify the climate's response, and would also produce significant global warming from doubled $\mathrm{CO}_{2}$. For example, Kirk-Davidoff and Lindzen (1993) summarized calculations implying that the paleoclimate record is consistent with extremely strong negative feedbacks in the tropics. They presented a simple climate model in which significant global mean temperature changes resulted from merely changing the transport of heat from the Equator toward the Poles. In principle this result is not surprising, because nonlinear feedbacks can create a situation in which moving heat from one location to another will change the global mean temperature (Robock, 1978). Until we see the details of KirkDavidoff and Lindzen's calculations, however, we will remain skeptical that the mechanism they advocate can account for the large global changes evident from the geologic record, while at the same time yielding a sensitivity to global mean radiative forcing $\left(\Delta T_{2 \times}\right)$ significantly smaller than conventional wisdom.

Similar comments apply to a study published by Lindzen and Pan (1994). These authors proposed a mechanism to translate Milankovitch forcing into glacialinterglacial variations, via changes in poleward heat flow by the Hadley circulation. They showed that the observed frequencies of glacial-interglacial variations could 
be explained by their theory. They concluded that "commonly used notions of climate sensitivity" are therefore "not relevant", and that "the present mechanism can readily produce major changes in climate (including, as a by product, changes in globally averaged temperature) in systems which are profoundly insensitive to a doubling of $\mathrm{CO}_{2}$." The calculations performed by Lindzen and Pan, however, only aimed at reproducing observations of the frequencies of glacial-interglacial transitions - not their amplitudes. Again, what is lacking is a plausible theory, presented in quantitative detail, that produces $2-5 \mathrm{~K}$ global temperature changes from Milankovitch forcing while remaining "profoundly insensitive to a doubling of $\mathrm{CO}_{2}$."

In our opinion, an important condition for plausibility of a climate theory is that it reproduce observed relationships between surface temperature $\left(T_{\mathrm{S}}\right)$ and satellite measurements of infrared radiation flux to space $\left(F_{\mathrm{IR}}\right)$. These observed relationships have long been used to infer that $\Delta T_{2 \times}$ lies in the range of GCMbased conventional wisdom. The argument comes from the high correlation seen between $F_{\mathrm{IR}}$ and $T_{\mathrm{S}}$, with a slope of about $2 \mathrm{~W} \mathrm{~m}^{-2} \mathrm{~K}^{-1}$ over most of the $T_{\mathrm{S}}$ domain (Warren and Schneider, 1979). Recall that doubled $\mathrm{CO}_{2}$ produces a radiative forcing of about $4 \mathrm{~W} \mathrm{~m}^{-2}$. It follows that the observed slope corresponds to $\Delta T_{2 \times} \sim 2 \mathrm{~K}$ (without taking albedo feedback into account). Note that $2 \mathrm{~W} \mathrm{~m}^{-2}$ $\mathrm{K}^{-1}$ is less than half the slope - implying more than twice the climate sensitivity - of a simple blackbody radiator, i.e., $4 \sigma T_{\mathrm{S}}^{3}=5.4 \mathrm{~W} \mathrm{~m}^{-2} \mathrm{~K}^{-1}$ for $T_{\mathrm{S}}=288 \mathrm{~K}$, where $\sigma$ is the Stefan-Boltzmann constant. In GCMs the main process boosting $\Delta T_{2 \times}$ is positive water vapor feedback. In the models, warmer temperatures lead to greater amounts of atmospheric water vapor, a potent greenhouse gas. Enhanced water vapor, in turn, traps more infrared flux, lowering the slope $\mathrm{d} F_{\mathrm{IR}} / \mathrm{d} T_{\mathrm{S}}$. Recent studies have shown directly that the GCM-simulated connections among $T_{\mathrm{S}}$, water vapor and $F_{\mathrm{IR}}$ agree with observations (Raval and Ramanathan, 1989; Rind $e t$ al., 1991).

In short, GCMs meet our condition of plausibility by agreeing with the satellite data. It seems doubtful to us that such agreement could be achieved in a model dominated by negative water vapor feedback, as advocated by Lindzen (1990). The point made by Sun and Lindzen (1993), that "the water vapor content of the air above the trade inversion over the subtropics is not directly related to the sea surface temperature immediately below", is certainly reasonable. Nevertheless the satellite data appear to argue strongly for an indirect effect amounting to positive water vapor greenhouse feedback.

We do not mean to imply that the issue is decided. The satellite observations discussed above relate $F_{\mathrm{IR}}$ to $T_{\mathrm{S}}$ by examining different points in space at the same time, or by examining the same points at different times in the cycle of the seasons. There is no guarantee that the correlation thus obtained will be the same as that between globally averaged $F_{\mathrm{IR}}$ and globally averaged $T_{\mathrm{S}}$ in a changing climate. The relatively low value of $\mathrm{d} F_{\mathrm{IR}} / \mathrm{d} T_{\mathrm{S}}$ observed from correlations of different latitudes could simply reflect warmer sea surface temperatures lying under the rising branch 
of the tropical Hadley or Walker circulations. In these regions there is more water vapor and cloud cover to trap outgoing IR, compared with areas under sinking air. Correlations obtained by observing individual points during the seasonal cycle could arise mainly through seasonal movement of the Hadley cell. Note, however, that such effects would be limited to latitudes equatorward of about $\pm 30^{\circ}$. GCMs also exhibit positive water vapor feedback poleward of these latitudes, in agreement with satellite data (Del Genio et al., 1994). It is difficult for us to imagine that the relationship between globally averaged $F_{\mathrm{IR}}$ and globally averaged $T_{\mathrm{S}}$ will prove to be radically different from that implied by a straightforward interpretation of the satellite data.

The relationship between surface temperature and outgoing IR can be more complex in particular regions, especially in the tropics. Correlations of $F_{\mathrm{IR}}$ with $T_{\mathrm{S}}$ in the moist tropics, using the techniques discussed above, imply a positive water vapor feedback that becomes strong enough to initiate a runaway greenhouse effect. In other words, the correlations have $\mathrm{d} F_{\mathrm{IR}} / \mathrm{d} T_{\mathrm{S}}<0$ for the warmest sea surface temperatures (Warren and Schneider, 1979; Ramanathan and Collins, 1991) or, equivalently, for most locations within $25^{\circ}$ latitude of the Equator (Raval et al., 1994). The observed stability of tropical temperature indicates that some compensating negative feedback is operative, but the process or processes stabilizing tropical temperature are still very much at issue. Various possibilities have been considered (Hoffert et al., 1983; Ramanathan and Collins, 1991, 1993; Hartmann and Michelsen, 1993). Alternatively, it may be that near the Equator, the aliasing effects discussed above make the correlations unreliable indicators of the large-scale response to climatic changes. Perhaps a better indication comes from the study of Chou (1994), which examined satellite-observed fluxes over the entire Pacific from $30^{\circ} \mathrm{S}$ to $30^{\circ} \mathrm{N}$. Comparing a selected El Niño with a non-El Niño period, Chou found $\mathrm{d} F_{\mathrm{IR}} / \mathrm{d} T_{\mathrm{S}} \sim 22 \mathrm{~W} \mathrm{~m}^{-2} \mathrm{~K}^{-1}$. If this result is statistically significant, it implies a strong negative feedback from water vapor or other causes in the tropics.

It is worth noting that Chou's results are not inconsistent with the climate sensitivity inferred by paleocalibration. From changes in tropical temperature relative to global mean temperature reconstructed for different paleoclimates (Hoffert and Covey, 1992) we estimate $\Delta T_{\text {tropical }} / \Delta T_{\text {mean }} \sim 1 / 5$. For a global mean radiative damping rate of $\sim 2 \mathrm{~W} \mathrm{~m}^{-2} \mathrm{~K}^{-1}$ (as inferred by Hoffert and Covey), the tropical radiative damping would then be $\sim 10 \mathrm{~W} \mathrm{~m}^{-2} \mathrm{~K}^{-1}$. Combining Chou's value of $\mathrm{d} F_{\mathrm{IR}} / \mathrm{d} T_{\mathrm{S}}$ and his corresponding result for solar flux changes gives $13 \mathrm{~W} \mathrm{~m}^{-2}$ $\mathrm{K}^{-1}$.

To summarize, in our opinion the satellite observations do not directly prove or disprove the conventional wisdom about the magnitude of $\Delta T_{2 \times}$. They do, however, provide relevant constraints that models predicting future climate should satisfy. GCMs that yield conventional-wisdom values of $\Delta T_{2 \times}$ also generally reproduce the observed pointwise correlations of $F_{\mathrm{IR}}$ with $T_{\mathrm{S}}$. Models such as those developed by Kirk-Davidoff and Lindzen should be published and subjected 
to the same tests. By the same token, of course, GCMs should be examined for consistency with Chou's recent results.

\section{Paleocalibration for the Eocene Earth}

Our inferences from paleocalibration would be put on a firmer foundation if they could be confirmed with more data points representing additional time intervals of Earth history. Here we add a third data point, representing an interval of Earth history that is located temporally between the Last Glacial Maximum and the Cretaceous.

The early Eocene climate was probably the warmest since the Cretaceous (e.g., Shackleton and Boersma, 1981; Wolfe, 1985; Barron, 1987; Crowley and North, 1991; Cerling, 1992; Sloan and Barron, 1992). Surface geography for the early Eocene was similar to today's with the following differences: Australia was in a more southerly position than today, located adjacent to Antarctica; India was located in the tropics and had not yet collided with Asia; the Mediterranean was larger than it currently is; the Himalayas were not as great in elevation; also the Rockies, Andes, and Transantarctic Mountains may have been somewhat reduced in elevation. The polar regions had little or no ice and subtropical plants existed within the Arctic Circle. On the other hand tropical temperatures were similar to today's values (Zachos et al., 1994). As shown below (Figure 1), the Eocene appears to be an extreme case in which tropical temperatures were no warmer, and perhaps even colder, than at present despite significant global mean warming. If any era exemplifies Lindzen's theory of global change through changes in Equator-to-Pole heat distribution, the Eocene should.

Solar output 55 million years ago was similar to that of the present day to within $\sim 0.5 \%$ (e.g., Fig. 5 of Crowley et al., 1991). Surface albedo would have been less than present during the Eocene due to: (1) lack of most, if not all, perennial continental and sea ice; (2) higher sea levels, leading to greater coverage of oceans; (3) presence of deciduous forests at high latitudes of both hemispheres; and (4) lack of extensive deserts. Estimates of atmospheric $\mathrm{CO}_{2}$ during the early Eocene come from theoretical models of Berner (1991; $2 \times$ preindustrial) and from geochemical interpretations of organic carbon (Freeman and Hayes, 1992: 2×; Arthur et al., 1991: 3-6x) and soil nodules (Cerling, 1992: $2 \times$ ). These estimates agree that $\mathrm{CO}_{2}$ was higher than present, but they vary over a broad range of 2 to 6 times preindustrial values. There is some thought that methane concentrations may have been higher than present during the Eocene due to extensive areas of swamps and wetlands (Sloan et al., 1992), but there is no direct evidence for this. There is no evidence whatsoever regarding atmospheric aerosols during this time (D. Rea, personal communication).

Increased atmospheric carbon dioxide is probably the dominant term in Eocene radiative forcing compared with the present. For the contribution to $\Delta Q$ from $\mathrm{CO}_{2}$ 


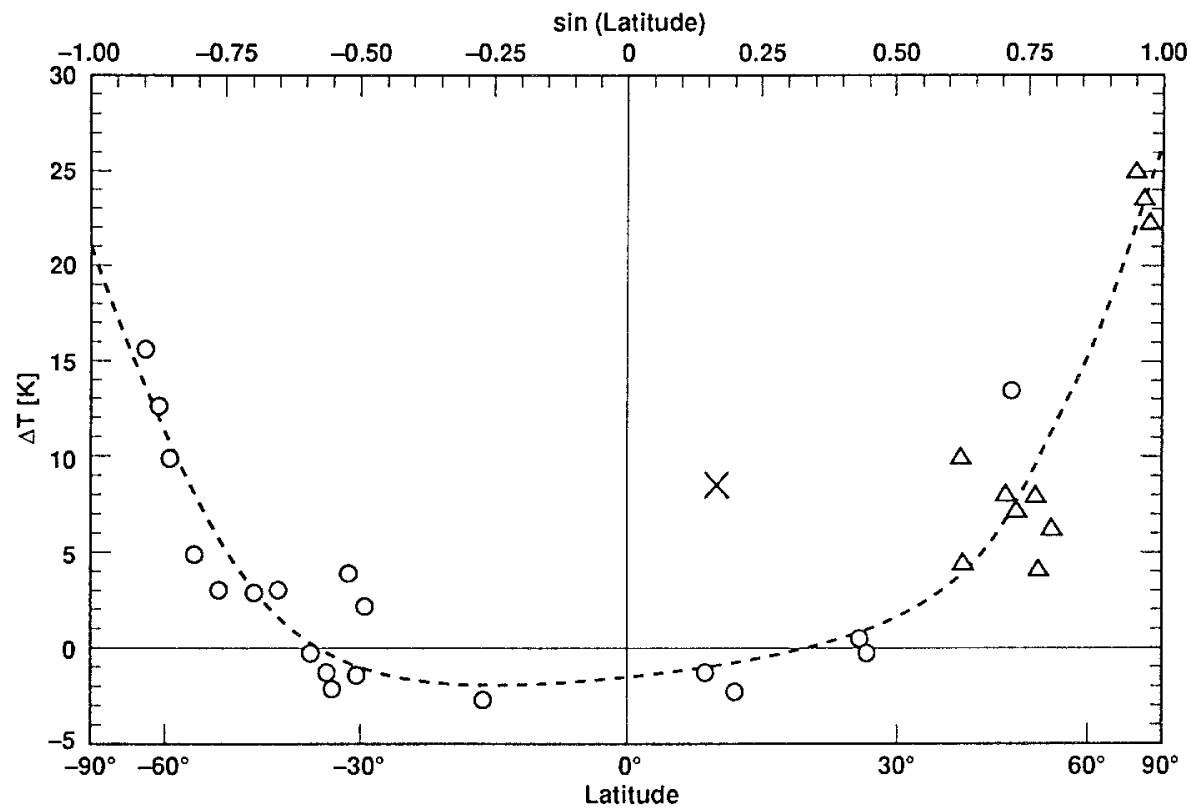

Fig. 1. Paleotemperature data vs. paleolatitude for the early Eocene. $\Delta T$ is the difference between Eocene and present-day surface temperature at each point; the dashed line is a least-squares fit to the data points. Circles show marine data (Zachos et al., 1994), triangles show continental data (Sloan and Barron, 1992), and the ' $x$ ' denotes a single marine data point excluded from the analysis because it occurs in a modern-day upwelling zone whose anomalously cool temperature overestimates $\Delta T$.

we take the full range of estimates discussed above, 2-6 times the preindustrial value. Using logarithmic scaling from $4.4 \mathrm{~W} \mathrm{~m}^{-2}$ for $\mathrm{CO}_{2}$ doubling, this gives a contribution of $7.9 \pm 3.5 \mathrm{~W} \mathrm{~m}^{-2}$. We neglect possible contributions from methane. Of the four above-mentioned factors that contribute to a change in surface abledo, lack of ice probably dominates forest growth and lack of deserts (Bonan et al., 1992). Covey et al. (1991) estimated that 2 to $3 \mathrm{~W} \mathrm{~m}^{-2}$ radiative forcing would result from the complete disappearance of sea ice from the present-day Earth, but we have excluded sea ice changes from our definition of $\Delta Q$ because we want to include such changes in the feedback processes measured by the paleocalibration technique. Accordingly we consider only the remaining contributor to changes in surface albedo, namely higher sea levels and the resulting decrease in the fraction of relatively high-albedo land areas. (Replacing land with ocean could of course lead to increased cloud cover, negating the surface albedo decrease; such an effect is defined as feedback rather forcing in the paleocalibration method). As a crude first estimate we set $\Delta Q$ due to this effect at two-thirds the Hoffert and Covey (1992) estimate of Cretaceous $\Delta Q$ due to surface albedo effects. Two-thirds is of course a rather arbitrary proportion, but it reflects the evidence that Eocene sea level was not quite as high as Cretaceous (Bluth and Kump, 1991). The result is $3.9 \pm 0.6 \mathrm{~W} \mathrm{~m}^{-2}$. Combining this with the contribution from increased $\mathrm{CO}_{2}$ (and 
taking the square root of the summed squared error estimates, as is appropriate for independent sources of error) gives a total $\Delta Q$ of $11.8 \pm 3.6 \mathrm{~W} \mathrm{~m}^{-2}$.

Early Eocene paleoclimate data indicate a world that was warmer than present, with greatest warming at high latitudes and little or no warming at low latitudes. Figure 1 shows the difference between mean annual Eocene and present surface temperatures as a function of latitude. We simply plotted local $\Delta T$ inferred from the paleodata at each available point on the globe together with the paleolatitude of each point (data taken from Sloan and Barron, 1992, and Zachos et al., 1994). We then fit a fourth-order polynomial in the sine of latitude to the data, weighting all points equally. The equal-weighting assumption is of course a crude approximation, but the data are so sparse that a more sophisticated treatment, such as interpolation in latitude-longitude space, seems unjustified to us. The globally averaged temperature change obtained from the integral of the fitted curve is $\Delta T=4.3 \mathrm{~K}$. (Note that both land and ocean points are used to obtain this value; if land points are excluded the same procedure gives $\Delta T=3.3 \mathrm{~K}$.) To obtain an error estimate for this figure we first note that the root-mean-square scatter of points about the fitted curve is $2.6 \mathrm{~K}$. This should be divided by the square root of the number of data points (29) to obtain the contribution to uncertainty in the global average: $\pm 0.5 \mathrm{~K}$. We must also include errors in translating proxy measurements to temperatures. Although these are more difficult to quantify, there appears to be consensus among those working with the ocean data that $\pm 2 \mathrm{~K}$ is a reasonable estimate for the total error in this category. Errors in the land data may be higher, but we will use $\pm 2 \mathrm{~K}$ because most of the data in Figure 1 come from the ocean (we do not divide $2 \mathrm{~K}$ by $\sqrt{29}$ because the errors in proxy-to-temperature conversion may well be systematic). Combining $\pm 0.5 \mathrm{~K}$ and $\pm 2 \mathrm{~K}$ in root-sum-square fashion then gives a final estimate of $\Delta T=4.3 \pm 2.1 \mathrm{~K}$.

In Figure 2 our Eocene estimates of $\Delta T$ and $\Delta Q$ are shown together with our earlier LGM and Cretaceous estimates (Hoffert and Covey, 1992), and the LGM estimate of Hansen et al. (1993). The figure illustrates application of the paleocalibration technique by representing the data in graphical terms, as a plot of $\Delta T$ versus $\Delta Q$ for several climate states in Earth history. By definition the presentday climate is a point at the origin. The three past climates, Eocene, Cretaceous and LGM, provide four more points (counting the independent LGM studies by us and by Hansen et al.). Conventional wisdom about Earth's climate sensitivity predicts that all points should lie in the range obtained from general circulation models, corresponding to $2-5 \mathrm{~K}$ warming for a doubling of atmospheric $\mathrm{CO}_{2}$. Within error limits, the points do indeed lie within the theoretically predicted range. The Eocene data, however, stand out as implying a significantly smaller climate sensitivity than the Cretaceous or LGM data. Using Equation (4) in Hoffert and Covey (1992), the Eocene $\Delta Q$ and $\Delta T$ values presented above imply $\Delta T_{2 \times}=1.6 \pm 0.9 \mathrm{~K}$. This result must be viewed with caution in light of the preliminary nature of our Eocene numbers. 


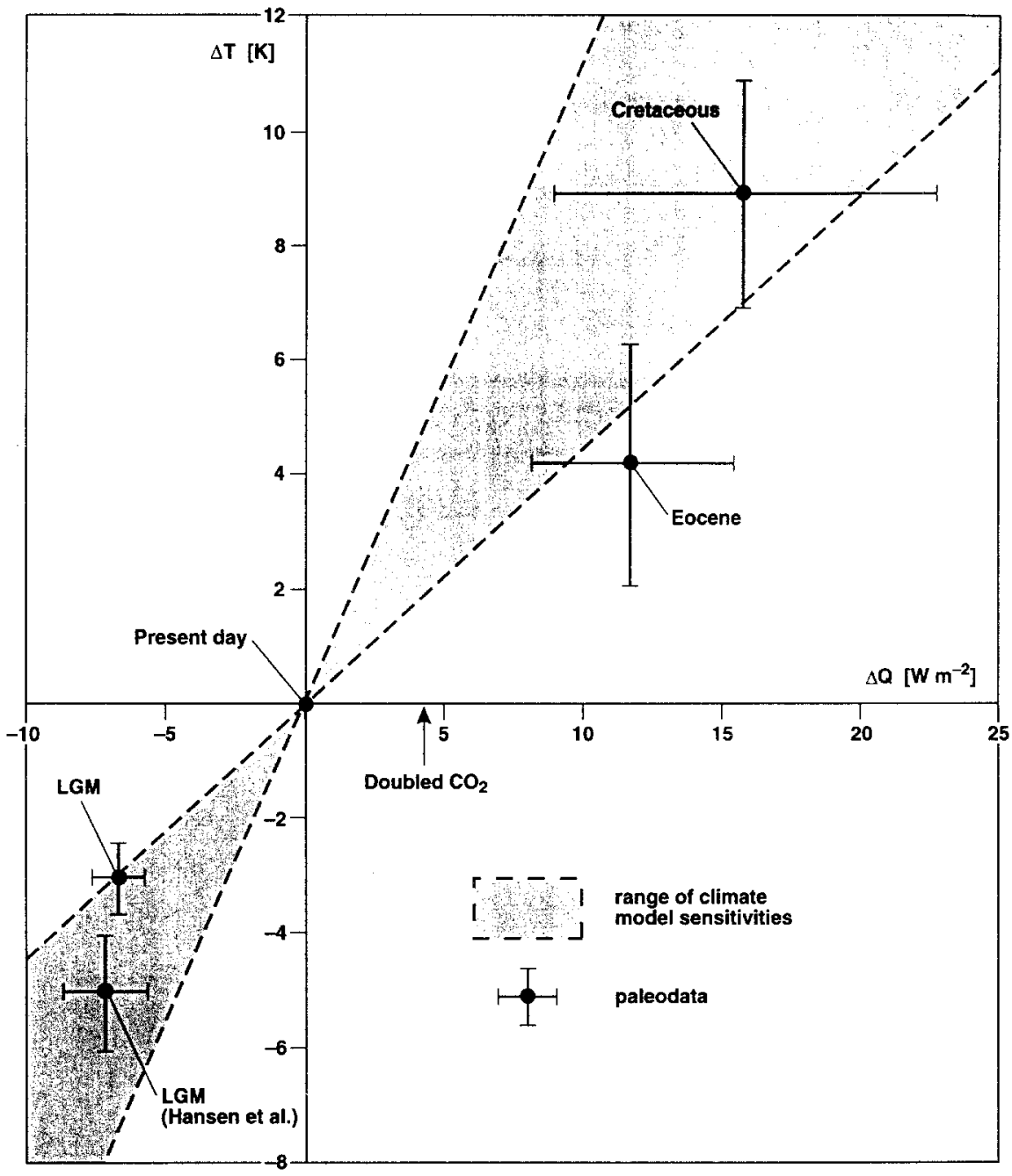

Fig. 2. Globally averaged $\Delta T$ vs. globally averaged $\Delta Q$ observed for several different paleoclimates. Shown for comparison is a range of climate sensitivity values obtained by theoretical models, equivalent to $2-5 \mathrm{~K}$ for $\mathrm{CO}_{2}$ doubling.

The most robust conclusion from all the paleocalibration results considered together is that the paleodata are approximately consistent with the range of climate sensitivity predicted by theory. The data points imply that Earth's true climate sensitivity lies somewhat in the lower half of the model-predicted range, and they allow the possibility that the actual climate sensitivity is slightly less than the lowest model-predicted value. However, a radical challenge to the GCM-based conventional wisdom, such as a claim that models overestimate $\Delta T_{2 \times}$ by an order of magnitude or more, would need to explain why the paleodata points in Figure 2 lie close to the model-predicted range. Correlation of course does not 
imply causation, but we would find it surprising if the actual causes of global mean temperature change involved the distribution rather than the global mean of radiative forcing, as suggested by Lindzen (1993). In that case the correlation of data points in Figure 2 would be due to global mean climate changes causing changes in global mean radiative forcing (just coincidentally with the $\Delta T / \Delta Q$ ratio predicted by climate models). But the correlation of the four data points we have compiled - those of Hoffert and Covey (1992), the Eocene point discussed above, and the present-day climate by definition at the origin - is clearly positive $(r=0.975 ; P<0.03)$. We would expect a negative correlation if the figure were revealing $\Delta T$ as the primary cause of $\Delta Q$ through the long-term carbon cycle. In that case, increased temperature could lead to increased weathering and hence enhanced removal of $\mathrm{CO}_{2}$ from the atmosphere, leading to decreased $\Delta Q$ (Rampino and Caldeira, 1994).

To reduce error limits and gain more confidence in the placement of data points in Figure 2, we need a more thorough examination of the data for all time intervals plotted. For the Eocene this is especially intriguing because of newly available Russian data for the Eurasian continent that imply a much larger value for $\Delta T$ than Western reconstructions indicate. While our compilation of mean annual temperature data produces an Eocene global warming of $4.3 \mathrm{~K}$ over present values, a Russian compilation indicates mean global Eocene warming of $9.7 \mathrm{~K}$ (Hoffert, 1993). The Russian data span the entire Eocene epoch while our compilation is restricted to the early Eocene (see Sloan and Barron, 1992). However, since the early Eocene is thought to have been the warmest interval, the Russian estimates should have a cold bias and not a warm bias in comparison to our data. The discrepancy between the Eocene temperature estimates is an issue that will have to be clarified in the future.

\section{Regional Climate Sensitivity}

The foregoing conclusion, that GCMs and paleodata are in rough agreement, generally applies only to the global average of temperature. Considering regional scales in addition to global-mean scales, we note that a GCM simulation of the early Eocene, while obtaining globally averaged $\Delta T$ consistent with the data, fails to obtain the sharp equator-to-pole surface $\Delta T$ gradient and the proper land-sea thermal contrast that the paleoclimate data suggest (Sloan et al., 1995; Sloan and Rea, 1995). The Eocene GCM results for 1, 2, and 6 times present atmospheric $\mathrm{CO}_{2}$ show global warming relative to the control simulation of $1.0,3.1$, and $6.3 \mathrm{~K}$ respectively, consistent with the paleodata's implication of about $4 \mathrm{~K}$ warming under 2-6 times preindustrial $\mathrm{CO}_{2}$. Figure 3 shows the annual mean, longitudeaveraged surface temperature increase over the present day for the $2 \times \mathrm{CO}_{2}$ and $6 \times \mathrm{CO}_{2}$ Eocene simulations. Also shown are the data points (same points as in Figure 1). It is evident from the figure that although the model's change in tem- 


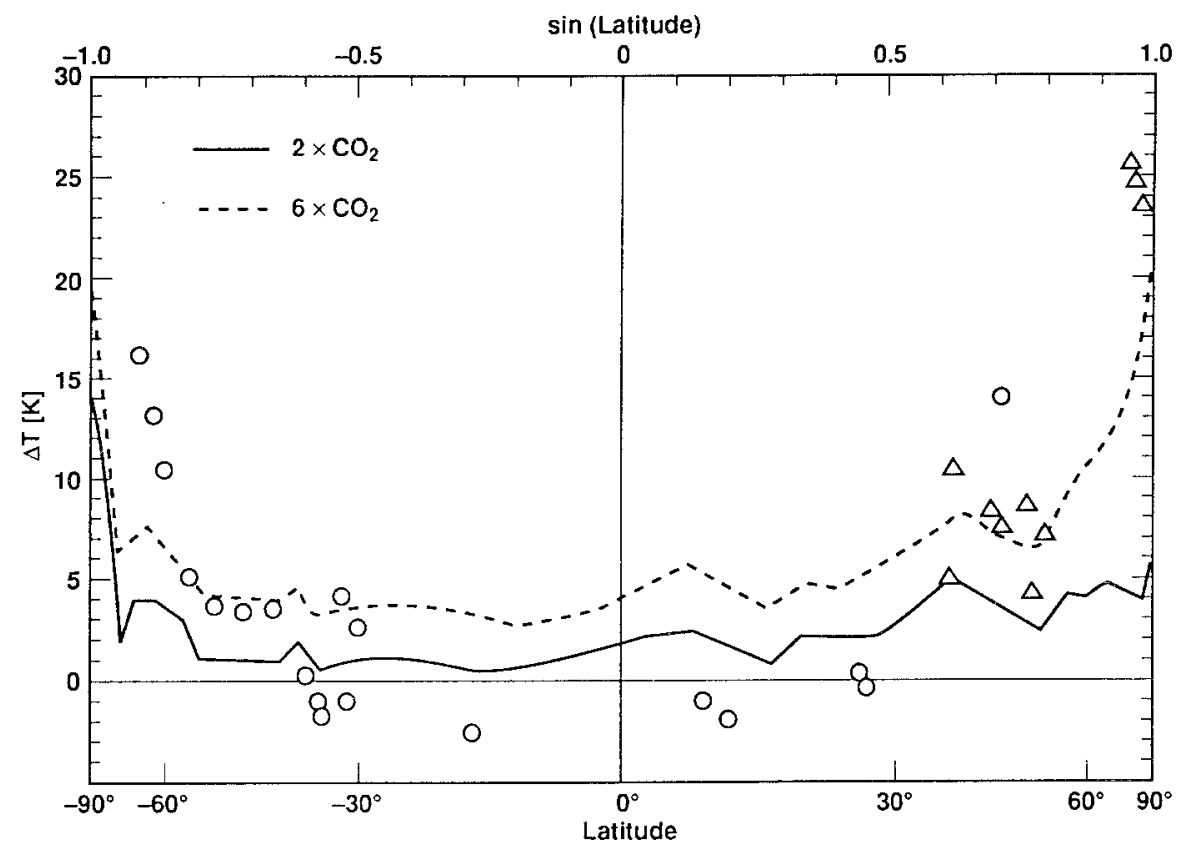

Fig. 3. Eocene paleodata (as in Figure 1) compared with two GCM simulations of the Eocene which assumed 2 and 6 times present levels of atmospheric $\mathrm{CO}_{2}$.

perature approximately agrees with the data in the global mean, the distribution of $\Delta T$ with latitude obtained by the model is far too uniform. Put another way, the model obtains nearly the same sharp Equator-to-Pole contrast in absolute $T$ for the Eocene as for the present day, whereas the geologic data imply that this temperature contrast was greatly reduced. For example, in mid-continental winters the model obtains below-freezing temperatures while data such as alligator and crocodile fossils clearly show that these areas did not undergo seasonal extremes during the Eocene (Sloan and Barron, 1992; Markwick, 1994; Sloan, in press). Similar problems were encountered in simulations of Cretaceous (Barron and Washington, 1984; Barron et al., 1993) and LGM (Manabe and Broccoli, 1985) climates. The tendency of current GCMs to predict relatively uniform global warming, including substantial tropical warming, in the face of observations that indicate that tropical surface temperatures have changed little in the geologic past is a key criticism of the reliability of these models (e.g., Horrell, 1990; Crowley, 1991; Lindzen, 1993).

We are left with a great irony in our effort to understand climatic change. When compared with paleodata, general circulation models show fair performance in the global mean but poor performance at the next levels of approximation, i.e., Equator-Pole and land-sea temperature contrasts. In fact the GCMs agree with each other less and less as the spatial scale of comparison is decreased (Grotch and MacCracken, 1991). There are important exceptions to this discouraging trend 
(COHMAP, 1988), but in general the predictions of GCMs, which give the most detailed simulations of climate available, are not reliable unless they are averaged to a global mean. Of course it is the regional details that matter to humans and to natural ecosystems.

A pessimist might conclude that for purposes of explaining past changes in climate or forecasting the future, GCMs are not any better than drastically simpler models, such as radiative-convective models that average over latitude and longitude. GCMs, however, have at least the potential for improvement. More rigorous examination of their inner workings (e.g., Gates, 1992), coupled with model-observation comparisons such as paleocalibration, may in time result in believable predictions of regional climate changes. Furthermore, GCMs even now provide a three-dimensional framework, constrained by known conservation laws for mass, momentum and energy, in which the effects of various climate-relevant processes may be tested. For example, possible attributes of tropical clouds and convection that would lead to negative water vapor feedback (Lindzen, 1990; Sun and Lindzen, 1993) could be programmed into a GCM, and the resulting effects on $\Delta T_{2 \times}$ assessed. Such an exercise would not be possible in a one-dimensional model.

\section{The Future of Paleocalibration}

A glance at Figure 2 shows that even though there is rough agreement between GCMs and paleodata, both the range of model results and the scatter and error bars in the data are large. Uncertainties in the data must be reduced if the data is to distinguish among differing model results, rather than simply confirm that the climate's sensitivity lies approximately within the range of estimates from different models. Reducing uncertainties in the data would also test the validity of the paleocalibration technique itself. If a version of Figure 2 with more careful placement of data points and smaller error bars shows the points lying securely on a line through the origin, then the case for interpolating to find $\Delta T_{2 \times}$ would be compelling. If on the other hand the correlation in $\Delta T-\Delta Q$ space were to disappear, the technique would clearly fail.

There are two ways to narrow uncertainty in the paleodata. First, we can try to refine estimates for the time periods we have already considered. This task would involve examining new data, such as the Russian estimates discussed above. It should also involve treating the data in a consistent way. For example, our error bounds for Ice Age $\Delta T$ accounted only for the scatter of points in the CLIMAP sea surface temperature data, not the widely held view that the CLIMAP data set systematically underestimates the globally averaged $\Delta T$. On the other hand, our error bounds for $\mathrm{CO}_{2}$ contribution to $\Delta Q$ during the Eocene and Cretaceous incorporate the full range of published estimates. This probably gives outlying estimates undue weight. Had we given less weight to the extreme range obtained 
by Arthur et al. (1992), for instance, our Eocene $\Delta Q$ estimate would have been reduced, and the Eocene point on Figure 2 would have fallen more within the model-predicted range of climate sensitivity. Analogous comments apply to the Cretaceous upper limit of $11 \times$ present-day $\mathrm{CO}_{2}$ (Berner, 1990) used by Hoffert and Covey (1992). The question of how to treat outlying estimates is equivalent to a question of how to give the best estimate of $\Delta T_{2 \times}$ - as a (mean value) \pm (standard error), implying the mean value is most likely, or simply as a range of equally-likely possibilities. Here, too, a consistent treatment would be desirable.

A second way to reduce paleodata uncertainty is to use more data points. Considering additional time periods for paleocalibration is especially attractive to us because it provides a test of the main assumption underlying the technique itself, namely the conventional wisdom that global mean temperature is (to first approximation) a unique function of global mean forcing. For example, in the Pliocene era 3 million years ago, globally averaged surface temperature was perhaps 1-3 K warmer than present, and, until recently, atmospheric $\mathrm{CO}_{2}$ was assumed to be about twice present levels (Crowley, 1991; Webb et al., 1993). More recent data, however, suggests that $\mathrm{CO}_{2}$ levels may have been only 30-50\% above preindustrial (Raymo and Rau, submitted), corresponding to a $\Delta Q$ of $1.7-2.6 \mathrm{~W} \mathrm{~m}^{-2}$. For $\Delta T=2 \mathrm{~K}$ the implied climate $\Delta T_{2 \times}$ is $3.4-5.3 \mathrm{~K}$, assuming as a crude first approximation that $\mathrm{CO}_{2}$ is the only factor in Pliocene $\Delta Q$.

Of course even a perfectly reliable estimate of $\Delta T_{2 \times}$ would have its limitations in forecasting the future. By definition, measuring sensitivity with a single number, based on global-mean equilibrium temperature change, excludes regional and temporal variations. This procedure can underestimate the magnitude of worldwide climate change if temperature changes of opposite sign in different regions cancel in the global mean. One interpretation of the Eocene paleodata, for example, has cooler tropical temperatures coexisting with warmer temperatures at higher latitudes. Perhaps the anomolously low Eocene $\Delta T_{2 \times}$ in Figure 2 should be considered in this light. Another potential problem is that, especially in view of nonlinear feedbacks involving water vapor and snow/ice albedo, $\Delta T_{2 \times}$ should not be expected $a$ priori to be a constant independent of the base state or the degree of perturbation. From Figure 2 it does not appear that this effect is severe enough to obscure the order-of-magnitude agreement between paleodata and model-based sensitivity calculations. The problem may appear, however, in the future. Using a more refined version of paleocalibration, as suggested above, may reveal nonlinearity in the relationship between $\Delta Q$ and $\Delta T$.

In conclusion, despite the limitations of paleocalibration in providing accurate and regionally relevant connections between past and future climates, we believe the technique is promising. One point is clear in any case. Paleoclimates give us the only real-world data that includes global changes of the magnitude predicted to occur as a result of human perturbation of the atmosphere during the next century. Except for waiting for such changes to occur, examination of paleoclimatic data is the only way to directly test the validity of the models that predict such changes. 


\section{Acknowledgements}

This work was performed under auspices of the U.S. Department of Energy's Environmental Sciences Division by the Lawrence Livermore National Laboratory under Contract W-7405-ENG-48. We thank Eric Barron, Tom Crowley and Dan Kirk-Davidoff for their comments on the manuscript.

\section{References}

Arthur, M. A., Hinga, K. R., Pilson, M. E., Whitaker, E., and Allard, D.: 1991, 'Estimates of $\mathrm{pCO}_{2}$ for the Last $120 \mathrm{Ma}$ Based on the $\mathrm{d}^{13} \mathrm{C}$ of Marine Phytoplanktic Organic Matter', [abs.], Eos (Transactions, American Geophysical Union 72, no. 17, suppl., 166.

Barron, E. J.: 1987, 'Eocene Equator-to-Pole Surface Ocean Temperatures: A Significant Climate Problem?', Paleoceanogr. 2, 729-739.

Barron, E. J.: 1993, Paper presented at the American Geophysical Union Spring Meeting, Baltimore, 24-28 May.

Barron, E. J., Fawcett, P. J., Peterson, W. H., Pollard, D., and Thompson, S. L.: 1995, 'A "Simulation" of Mid-Cretaceous Climate', Paleoceanogr., (in press).

Barron, E. J., Fawcett, P. J., Pollard, D., and Thompson, S. L.: 1993, 'Model Simulations of Cretaceous Climates: The Role of Geography and Carbon Dioxide', Phil. Trans. Roy. Soc. Lond. B 341, 307316.

Barron, E. J. and Washington, W. M.: 1982, 'Cretaceous Climate: A Comparison of Atmospheric Simulations with the Geologic Record', Palaeogeog., Palaeoclim., Palaeoecol. 40, 103-133.

Barron, E. J. and Washington, W. M.: 1984, 'Warm Cretaceous Climates: High Atmospheric $\mathrm{CO}_{2}$ as a Plausible Mechanism', in Sundquist, E. T. and Broecker, W. S. (eds.), The Carbon Cycle and Atmospheric $\mathrm{CO}_{2}$, Natural Variations, Archean to Present, American Geophysical Union, Washington, DC, pp. 546-553.

Berner, R.: 1990, 'Atmospheric Carbon Dioxide Levels over Phanerozoic Time', Science 249, 13821386 .

Berner, R.: 1991, 'A Model for Atmospheric $\mathrm{CO}_{2}$ over Phanerozoic Time', Amer. J. Sci. 291, 339-376.

Bluth, G. J. S. and Kump, L. R.: 1991, 'Phanerozoic Paleogeology', Amer. J. Sci. 291, 284-308.

Bonan, G. B., Pollard, D., and Thompson, S. L.: 1992, 'Effects of Boreal Forest Vegetation on Global Climate', Nature 359, 716-718.

Budyko, M. and Izrael, Y.: 1987, Anthropogenic Climate Changes, Gidrometeoizdat, Leningrad (in Russian; English translation by University of Arizona Press, 1990).

Cerling, T.: 1992, 'Carbon Dioxide in the Atmosphere: Evidence from Cenozoic and Mesozoic Paleosols', Amer. J. Sci. 291, 377-400.

Cess, R. D. and Potter, G. L.: 1988, 'A Methodology for Understanding and Intercomparing Atmospheric Climate Feedback Processes in General Circulation Models', J. Geophys. Res. 93, 83058314.

Chou, M.-D.: 1994, 'Coolness in the Tropical Pacific during an El Niño Episode', J. Clim. 7, 1684 1692.

CLIMAP Project members: 1976, 'The Surface of the Ice-Age Earth', Science 191, 1131-1137.

COHMAP Project Members: 1988, 'Climatic Changes of the Last 18,000 Years: Observations and Model Simulations', Science 241, 1043-1052.

Covey, C., Taylor, K. E., and Dickinson, R. E.: 1991, 'Upper Limit for Sea Ice Albedo Feedback Contribution to Global Warming', J. Geophys. Res. 96, 9169-9174.

Crowley, T:: 1990, 'Are There Any Satisfactory Geologic Analogs for Future Greenhouse Warming', J. Clim. 3, 1282-1292.

Crowley, T:: 1991, ' $\mathrm{CO}_{2}$ Changes and Tropical Sea Surface Temperatures', Paleoceanogr. 6, 387-394.

Crowley, T., Baum, S. K., and Hyde, W. T.: 1991, 'Climate Model Comparison of Gondwanan and Laurentide Glaciations', J. Geophys. Res. 96, 9217-9226. 
Crowley, T. and Kim, K.-Y.: 1995, 'Comparison of Longterm Greenhouse Projections with the Geologic Record', Geophys. Res. Lett., (in press).

Crowley, T. and North: 1991, Paleoclimatology, Oxford University Press, New York, 339 pp.

Del Genio, A. D., Kovari, W., Jr., and Yao, M.-S.: 1994, 'Climatic Implications of the Seasonal Variation of Upper Tropospheric Water Vapor', Geophys. Res. Lett. 21, 2701-2704.

Freeman, K. and Hayes, P.: 1992, 'Fractionation of Carbon Isotopes by Phytoplankton and Estimates of Ancient $\mathrm{CO}_{2}$ Levels, Global Biogeochem. Cycl. 6, 185-198.

Gates, W. L.: 1992, 'AMIP: The Atmospheric Model Intercomparison Project', Bull. Amer. Met. Soc. 73, 1962-1970.

Grotch, S. L. and MacCracken, M. C.: 1991, 'The Use of General Circulation Models to Predict Regional Climatic Change', J. Clim. 3, 286-303.

Guilderson, T. P., Fairbanks, R. G., and Rubenstone, J. L.: 1994, 'Tropical Temperature Variations since 20,000 Years Ago: Modulating Interhemispheric Climate Change', Science 263, 663-665.

Hansen, J., Johnson, D., Lacis, A., Lebedeff, S., Lee, P., Rind, D., and Russell, G.: 1981, 'Climatic Impact of Increasing Atmospheric Carbon Dioxide', Science 213, 957-966.

Hansen, J., Lacis, A., Ruedy, R., Sato, M., and Wilson, W.: 1993, 'How Sensitive is the World's Climate?', National Geogr. Res. Exploration 9, 142-158.

Hansen, J., Russell, G., Lacis, A., Fung, I., and Rind, D.: 1985, 'Climate Response Times: Dependence on Climate Sensitivity and Ocean Mixing', Science 229, 857-859.

Hansen, J., Sato, S., and Ruedy, R.: 1995, 'Wonderland Model: Radiative Forcing Experiments', (in preparation for J. Geophys. Res.).

Hartmann, D. L. and Michelsen, M. L.: 1993, 'Large-Scale Effects on the Regulation of Tropical Sea Surface Temperature', J. Clim. 6, 2049-2062.

Hecht, A.: 1985, Paleoclimate Analysis and Modeling, Wiley-Interscience Publishers, New York, $445 \mathrm{pp}$.

Hoffert, M. I.: 1993, Paper presented at the American Geophysical Union Spring Meeting, Baltimore, 24-28 May.

Hoffert, M. I. and Covey, C.: 1992, 'Deriving Global Climate Sensitivity from Palaeoclimate Reconstructions', Nature 360, 573-576.

Hoffert, M. I., Flannery, B. P., Callegari, A. J., Hsieh, C.-T., and Wiscombe, W.: 1983, 'EvaporationLimited Tropical Temperatures as a Constraint on Climate Sensitivity', J. Atmos. Sci. 40, 16591668.

Horrell, M.: 1990, 'Energy Balance Constraints on ${ }^{18} \mathrm{O}$ Based Paleo-Sea Surface Temperature Estimates', Paleoceanog. 5, 339-348.

Imbrie, J. and Imbrie, K. P.: 1979, Ice Ages: Solving the Mystery, Enslow Publishers.

Kellogg, W.: 1977, Effects of Human Activities on Global Climate, WMO Report No. 486, World Meteorology Organization, Geneva.

Kerr, R.: 1993, 'Fossils Tell of Mild Winters in an Ancient Hothouse', Science 261, 682.

Kirk-Davidoff, D. B. and Lindzen, R. S.: 1993, Paper presented at the American Geophysical Union annual Fall Meeting, San Francisco, CA.

Lindzen, R. S.: 1990, 'Some Coolness Concerning Global Warming', Bull. Amer. Meteorol. Soc. 71, 288-299.

Lindzen, R. S.: 1993, 'Paleoclimate Sensitivity', Nature 363, 25-26.

Lindzen, R. S.: 1995, 'How Cold Would We Get under $\mathrm{CO}_{2}$-Less Skies?', Physics Today, February issue, 78-80.

Lindzen, R. S. and Pan, W.: 1994, 'A Note on Orbital Control of Equator-to-Pole Heat Fluxes', Clim. Dynam. 10, 49-57.

Lorius, C., Jouzel, J., Raynaud, D., Hansen, J., and Le Treut, H.: 1990, 'The Ice-Core Record: Climate Sensitivity and Future Greenhouse Warming', Nature 347, 139-145.

Manabe, S. and Broccoli, A. J.: 1985, 'A Comparison of Climate Model Sensitivity with Data from the Last Glacial Maximum', J. Atmos. Sci. 42, 2643-2651.

Markwick, P. J.: 1994, "Equability", Continentality, and Tertiary "Climate": The Crocodilian Perspective', Geology 22, 613-616.

Mitchell, J. F. B., Senior, C. A., and Ingram, W. J.: 1989 , ' $\mathrm{CO}_{2}$ and Climate: A Missing Feedback?', Nature 341, 132-134. 
Ramanathan, V. and Collins, W.: 1991, 'Thermodynamic Regulation of Ocean Warming by Cirrus Clouds Deduced from Observations of the 1987 El Niño', Nature 351, 27-32.

Ramanathan, V. and Collins, W.: 1993, 'A Thermostat in the Tropics?', Nature 361, 410-411.

Rampino, M. R. and Caldeira, K.: 1994, 'The Goldilocks Problem: Climatic Evolution and Long-Term Habitability of the Terrestrial Planets', Ann. Rev. Astron. Astrophys. 32, 83-114.

Raval, A., Oort, A. H., and Ramaswamy, V.: 1994, 'Observed Dependence of Outgoing Longwave Radiation on Sea Surface Temperature and Moisture', J. Clim. 7, 807-821.

Raval, A. and Ramanathan, V.: 1989, 'Observational Determination of the Greenhouse Effect', Nature 342, 758-762.

Raymo, M. E. and Rau, G. H.: 'Mid-Pliocene Warmth: Stronger Greenhouse and Stronger Conveyor', Science, (submitted).

Rind, D., Chiou, E.-W., Chu, W., Larsen, J., Oltmans, S., Lerner, J., McCormick, M. P., and McMaster, L.: 1991, 'Positive Water Vapor Feedback in Climate Models Confirmed by Satellite Data', Nature 349, 500-503.

Rind, D. and Peteet, D.: 1985, 'Terrestrial Conditions at the Last Glacial Maximum and CLIMAP Sea-Surface Temperature Estimates: Are They Consistent?', Quat. Res. 24, 1-22.

Robock, A.: 1978, 'Internally and Externally Caused Climate Change', J. Atmos. Sci. 35, 1111-1122.

Sellwood, B. W., Price, G. D., and Valdes, P. J.: 1994, 'Cooler Estimates of Cretaceous Temperatures', Nature 370, 453-455.

Shackleton, N. J. and Boersma, A.: 1981, 'The Climate of the Eocene Ocean', Geol. Soc. London J. 138, 153-157.

Shine, K. P., Derwent, R. G., Wuebbles, D. J., and Morcrette, J.-J.: 1990, 'Radiative Forcing of Climate', in Houghton, J. T., Jenkins, G. J., and Ephraums, J. J. (eds.), Climate Change: The IPCC Scientific Assessment, Cambridge University Press, New York, pp. 41-68.

Sloan, L. Cirbus: 1994, 'Equable Climates During the Early Eocene: Significance of Regional Paleogeography for North American Climate', Geology 22, 881-884.

Sloan, L. Cirbus and Barron, E. J.: 1992, 'Eocene Climate Model Results: Quantitative Comparison to Paleoclimatic Evidence', Palaeogeog., Palaeoclim., Palaeoecol. 93, 183-202.

Sloan, L. Cirbus and Rea, D. K.: 1995, 'Atmospheric $\mathrm{CO}_{2}$ of the Early Eocene: A General Circulation Modeling Sensitivity Study', Glob. Plan. Change, (in press).

Sloan, L. Cirbus, Walker, J. C. G., and Moore, T. C., Jr.: 1995, 'The Role of Oceanic Heat Transport in Early Eocene Climate', Paleoceanogr. 10, 347-356.

Sloan, L. Cirbus, Walker, J. C. G., Moore, T. C., Jr., Rea, D. K., and Zachos, J. C.: 1992, 'Possible Methane-Induced Polar Warming in the Early Eocene', Nature 357, 320-322.

Sun, D.-Z. and Lindzen, R. S.: 1993, 'Distribution of Tropical Tropospheric Water Vapor', J. Atmos. Sci. 50, 1644-1659.

Walker, J. C. G. and Sloan, L. Cirbus: 1992, 'Something is Wrong with Climate Theory', Geotimes 37, 16-18.

Warren, S. G. and Schneider, S. H.: 1979, 'Seasonal Simulation as a Test for Uncertainties in the Parameterizations of a Budyko-Sellers Zonal Climate Model', J. Atmos. Sci. 36, 1377-1391.

Webb III, T., Crowley, T. J., Frenzel, B., Gliemeroth, A.-K., Jouzel, J., Labeyrie, L., Prentice, I. C., Rind, D., Ruddiman, W. F., Sarnthein, M., and Zwick, A.: 1993, 'Group Report: Use of Paleoclimatic Data as Analogs for Understanding Future Global Changes', in Global Changes in the Perspective of the Past, John Wiley \& Sons, Chichester, England, pp. 50-71.

Wigley, T. M. L. and Schlesinger, M. E.: 1985, 'Analytical Solution for the Effect of Increasing $\mathrm{CO}_{2}$ on Global Mean Temperature', Nature 315, 649-652.

Wolfe, J.: 1985, 'Distribution of Major Vegetational Types During the Tertiary', in Sundquist, E. T. and Broecker, W. S. (eds.), The Carbon Cycle and Atmospheric $\mathrm{CO}_{2}$ : Natural Variations Archean to Present, Geophys. Monogr. 32, Am. Geophys. Union, Washington, D.C., pp. 357-375.

Zachos, J. C., Stott, L. D., and Lohmann, K. C.: 1994, 'Evolution of Early Cenozoic Marine Temperatures', Paleoceanog. 9, 353-387. 